\title{
Religious Diversity at Work: The Perceptual Effects of Religious Discrimination on Employee Engagement and Commitment
}

\author{
Leila Canaan Messarra \\ Lebanese American University \\ E-Mail: 1masara@lau.edu.lb
}

\begin{abstract}
As the workforce is becoming more diversified in terms of culture, ethnicity, and religion, many individual values are carried over to the workplace. Now, in the post9/11 world, employees working in religiously diverse organizations might be prone to increased interpersonal conflicts and misunderstandings because of their religious affiliation. Yet, exploring the effects of religious diversity in organizations is still in its embryonic stages. This study investigated the perceptual effects of perceived religious discrimination on employee work-related behaviors, mainly commitment and engagement. The study surveyed 548 employees working in religiously diverse organizations. The findings suggested that when workers perceive religious discrimination in their organization, their commitment and engagement are affected. It is recommended that managers in general and specifically human resource managers devise strategies and develop management interventions to mitigate the negative organizational and personal consequences of religious discrimination in the workplace. Further studies should assess the effects of employees' perceived religious discrimination on other behavioral outcomes.
\end{abstract}

Keywords: Employee Engagement, Commitment, Religious Discrimination, Religious Diversity

\section{INTRODUCTION}

The research on religious diversity in organizations is still in its embryonic stages; however, with globalization and increased immigration, it is imperative to study this issue as a new challenge within a diverse workforce. Workforce diversity suggests that the workplace comprises people with different characteristics, such as race, gender, ethnicity, language, color, religion, and health status (Chan, 2011). Most Western literature on workplace diversity has tackled issues like gender, ethnicity, race, age, sexual orientation, and the like, although it has remained relatively tacit 
regarding religious diversity. Now, in the post-9/11 world, this issue has surfaced as a topic of interest both within and outside of the workplace in general. Currently, religious discrimination has surfaced as a new managerial challenge that needs to be addressed. The number of religious discrimination grievances has been rising faster than gender or race claims (Weiss, 2008). According to the Equal Employment Opportunity Commission (EEOC, 2011) in the US, 3,790 religious bias complaints were filed in 2010 compared to 2,127 in 2001 , with settlements reaching nearly $\$ 10$ million (to the researcher's knowledge, no statistics exists on religious discrimination claims for other countries).

As the workforce is becoming more diversified in terms of culture, ethnicity, and religion, many individual values are carried over to the workplace. Hence, employees are most likely to bring their religious beliefs with them to the office. According to Oliveira (2004), Mitroff and Denton (1999), and Cavanagh (1999), organizations that openly encourage their employees to express their spirituality are likely to become more successful. Still, what if the colleagues or supervisors do not share or embrace the beliefs of their coworkers? What if they discriminate against them because of different religion? This can affect both employers and employees.

A limited number of scholarly publications focused on religious discrimination and/or religious diversity management within organizations. Previous discrimination studies have examined such characteristics as age, gender, race and disability, and their relation to organizational behavioral outcomes (see for example Channar, Abbassi, \& Ujan, 2011; Ensher et al., 2001; Rabl \& del Carmen Triana, 2013). However, no study to date has examined the relationship between religious discrimination and organizational behavioral outcomes. The purpose of this study is twofold. First, it attempts to fill the gap in the literature on religious discrimination and strives to increase the level of organizational awareness about the importance of perceived religious discrimination in the workplace. Second, it examines the perceptual effects of religious discrimination on organizational behavioral outcomes, mainly employee engagement and organizational commitment

The study opens with a literature review on religious discrimination followed by an overview of the Lebanese environment where the study took place and an overview of the theoretical background. Next, it includes a literature review on organizational commitment and engagement and draws the hypotheses. Then, the methodology is presented followed by a discussion of the results, conclusion, and a section on limitations and implications. 


\section{LITERATURE REVIEW AND HYPOTHESIS}

\section{Religious Discrimination}

Perceived discrimination refers to an individual's perception that he/she is unfairly treated because of his/her group membership (Sanchez \& Brock, 1996). According to Robbins and Judge (2013), people of different religious faiths often get into conflict. Employees in religiously diverse organizations might be prone to increased interpersonal conflicts and misunderstandings, which can increase prejudice between co-workers (Day, 2005). Religious discrimination is defined as "valuing or treating a person or group differently because of what they do or do not believe or because of their feelings towards a given religion" ("Religious Discrimination", 2013). In this study, perceived religious discrimination is defined as an individual's perception that he/she is unfairly treated because of his/her belonging to a certain religious group or sect.

Whether discrimination is overt or covert, what matters is how employees perceive discrimination. According to Ensher, Grant-Vallone, and Donaldson (2001), discrimination, as perceived by employees, can affect key areas, such as recruitment, organizational culture, compensation, employee relations, and legislative decisions, and ultimately, it can have a financial effect on organizations. Sanchez and Brock (1996) reported a link between perceived discrimination and increased work tension and job turnover.

Discrimination can range from simple comments, for example, about grooming or traditional dress, to termination from work. Nevertheless, current studies that deal with religion in the workplace focus mainly on management practices, such as dress codes, and the scheduling of religious holidays or consider them when planning meetings and/or other activities (see for example Borstorff \& Arlington, 2011; Wolkinson \& Nichol, 2008). According to Morgan (2004), it is a common practice for individuals nowadays to express their personal religious views and to seek religious accommodations in the workplace. This could cause some conflicts for managers. Still, these issues merely scratch the surface of deeper issues at hand, such as behavioral outcomes that affect the organizational performance like employee commitment and engagement. Having dealt with issues of religious diversity for generations, Lebanon exemplifies an environment that attempts to manage them harmoniously, and it offers an example of what organizations have just begun to experience. 


\section{The Case of Lebanon and Theoretical Background}

Lebanon, a small country of only 10,452 $\mathrm{km}^{2}$, comprises 17 different government-acknowledged sects (Maktabi, 1999). It is governed through a confessionalist system "based on the belief that each religious community is a separate entity the interests of which are distinct from those of other sects" (Dajani, 1992). According to Dajani (1992), "the confessional identity of the Lebanese is further strengthened in various domains of social interaction, such as youth association... geographical distribution of population... education and the schooling system.... and political divisions." However, since, by law, government institutions distribute power among different religious communities, the public sector has suffered. Hiring in the public sector is based on religion rather than qualifications to ensure fair representation of all religious groups (Aoun, 2007). However, the private sector did not suffer as much. Rather, it evolved. Their hiring is more qualifications-based (Aoun, 2007).

In general, Lebanese people strongly affiliate with religion, which determines their social and political identity rather than the ceremonial practice of devotion (Ghazi, 1997). Thus, diversity in Lebanon is mostly understood in terms of religious belonging (Hudson, 1999). Under this kind of identification, we propose that the Lebanese assume group identity based on religion and the application of the social categorization theory. According to Van Knippenberg et.al. (2004), social categorization theory stresses that "similarities and differences are used as bases for categorizing self and others into groups, with subsequent categorization distinguishing between one's own in-group and one or more out-group" (p. 1009). Cantone (2011) emphasized that individuals categorize specific religious groups as 'in' or 'out' groups and discriminate against the opposing groups based on their social identity. Accordingly, this study argues that individuals identify with their religious group and are more likely to discriminate against individuals who belong to a different religious group, leading to in-group favoritism or inequality in the workplace. This study defines inequality as treating an individual based on his/her membership in a group rather than merit (Wilson, 1997).

\section{Commitment}

Organizational commitment refers to an individual's psychological bond with or feelings about the organization. As defined by Mowday et al. (1982, p. 27), organizational commitment is "the strength of an individual's identification with and involvement in an organization." It is conceptualized as an affective response resulting 
from an evaluation of the work situation that links the individual to the organization" (Baek-Kyoo \& Taejo, 2009, p. 51).

A large volume of research has been devoted to studying organizational commitment, including its forms, antecedents, dimensions, and outcomes. A common agreement among scholars is that highly committed employees contribute more to the performance of the organization (see for example Chen, Silverthorne, \& Hung, 2006; Riketta, 2002).

Meyer and Allen (1997) distinguished three types of commitment and developed a scale to measure them. These are: (a) affective commitment, defined as one's emotional attachment to, identification with, and involvement in the organization; (b) continuance commitment, an employee's awareness of the costs associated with leaving the organization; and (c) normative commitment, described as an individual's emotional obligation to continue employment.

\section{Employee Engagement}

Most company-based definitions have considered engagement as an outcome whereas academic research has examined various facets of employee engagement, more specifically, the outcomes of engagement, the psychological state of the employee, and the two-way relationship between the organization and the employee (Markwick \& Smith, 2009). In sum, employee engagement is a term that comprises the psychological state, observable behavior, and attitude of an employee, which contributes positively to organizational effectiveness (Macey \& Schneider, 2008).

Maslach, Schaufeli, and Leiter (2001) defined engagement as a motivational process, a positive, fulfilling, affective-motivational state of work-related well-being. According to Brown (1996), engagement is closely associated with job involvement. Schaufeli et al. (2002) distinguished three interrelated dimensions of employee engagement and developed a scale to measure them. These are: (a) Vigor, defined as one's great spirit and strength within the workplace, his/her readiness to devote energy to the job, and his/her resilience in the face of challenges; (b) Dedication, an employee's feeling of being challenged as well as his/her passion, encouragement, and pleasure in the work place; (c) Absorption, described as being entirely focused and intensely captivated by one's own work, whereby time quickly passes and the employee has a tough time detaching him/herself from his/her own work.

\section{Commitment, Employee Engagement, and Religious Discrimination}

Gelade, Dobson, and Gibert (2006) reported that traditionally, "organizational attitudes, such as organizational commitment, are cognitive assessments that reflect 
characteristics of the work environment" (p. 543). An individual's commitment to the organization has been linked to fair treatment (Allen \& Meyer, 1990) and leadership behaviors (Mathieu \& Zajac, 1990). A study by Abdul Rashid, Sambasivan, and Johari (2003), which examined 202 managers in Malaysian companies, suggested that organizational commitment and corporate culture are interrelated.

Past research has indicated that the emotional state of the individual at work affects his/her behavioral outcome and work involvement (see for example Avey, et al., 2008; Ensher, Grant-Vallone \& Donaldson, 2001). When individuals feel that they have been discriminated against, this can lead to a feeling of injustice, stress, poor performance, and poor organizational commitment on the part of the victim (Dipboye \& Colella, 2005). Ensher, Grant-Vallone, and Donaldson (2001) found that higher perceived discrimination at work, as reported by employees, decreases the employees' organizational commitment and job satisfaction. Shellenbarger (1993) found that minorities who perceived discrimination on the job are more likely to change jobs; thus, they are less committed to their work, compared to their white counterparts. It can then be argued that when individuals feel mistreated or discriminated against because of their group membership, such as belonging to a certain religious group, they can develop negative work-related behaviors, such as decreased commitment levels. Thus, the researcher hypothesizes that individuals' work commitment will suffer if they perceive religious discrimination in their workplace. Thus,

H1: Religious discrimination and commitment are negatively related

H1a: Religious discrimination and affective commitment are negatively related.

$\mathrm{H} 1 \mathrm{~b}$ : Religious discrimination and normative commitment are negatively related.

H1c: Religious discrimination and continuance commitment are negatively related.

On the other hand, how a person relates to or fits in with his/her environment has a great effect on his/her behavioral engagement (Bono \& Judge, 2003). If an employee feels that his/her social identity is threatened, especially if this identity is a central component of his/her self-concept (Thompson, 1999), he/she is more likely to disengage psychologically or physically to cope with this situation (Major \& O'Brien, 2005). Within the current context, identity threats resulting from religious discrimination will more likely result in the worker being less engaged at work.

Scholarly literature on engagement has emphasized that harmonious relation between coworkers fosters a psychological sense of safety in the work environment. A study by Avey et al. (2008) found a positive relationship between positive emotions and engagement. Kahn (1990) suggested that employee engagement at work varies based on the ways in which they "psychologically" experience their jobs. Additionally, 
Schaufeli and Van Rhenen (2006) attributed increased productivity of engaged employees to positive emotions they experience at work. Harter, Schmidt, and Keyes (2003) concluded that employee engagement "generates higher frequency of positive affect (job satisfaction, commitment, joy, fulfillment, interest, caring)," which in turn affects retention and efficiency.

According to Markos and Waltair (2010), what drives employee engagement is mostly non-financial in nature. Seijts and Crim (2006) highlighted ten factors that drive employee engagement, called "The Ten C's of Employee Engagement". These are connect (relationship between manager and employee), career (room for career advancement), clarity (understanding the goals and vision), convey (regular feedback and expectations), congratulate (praise and recognition), contribute (involvement), control (control over his or her job), collaborate (teamwork), credibility (feeling of pride in one's job or organization), and confidence (confidence in employee's own ability, or in the credibility of the team or organization). If the employee perceived these factors positively, then his or her engagement level would most likely increase. Based on the above, teamwork and manager/employee relationship are important attributes of employee engagement, which can be negatively affected by discrimination. Generally, the higher the engagement level, the higher the performance, feedback, appraisal, and the lower the turnover rate (Perrin, 2003).

Therefore, given the positive relationship between the emotional state of the individual and his/her engagement and the negative relation between perceived discrimination and work related behaviors, the following hypotheses can be drawn:

$\mathrm{H} 2$ : Religious discrimination and employee engagement are negatively related

H2a: Religious discrimination and vigor are negatively related.

$\mathrm{H} 2 \mathrm{~b}$ : Religious discrimination and dedication are negatively related.

$\mathrm{H} 2 \mathrm{c}$ : Religious discrimination and absorption are negatively related.

\section{METHODOLOGY}

The current researcher's aim is to assess perceptual effects of perceived religious discrimination on employees' commitment and engagement in the workplace. The data was collected using a questionnaire. The sample comprised 9 organizations from different industries within the Lebanese private sector. Firms from the financial sector dominated the sample.

After consulting with the human resource managers, the targeted organizations had to have employees from diverse religious groups (in Lebanon, a civil status document is required with the job application, which includes the individual's religion and sect). The use of Purposive Sampling permits the selection of a sample that serves 
the exact purpose of the study even if the selected sample is not totally representative (Zikmund, 2002). A cover letter attached to the questionnaire indicated the purpose of the study with assurance of anonymity. Out of 615 questionnaires, 548 employees successfully completed the survey, yielding a response rate of $89 \%$.

The questionnaire in this study had three parts comprising 51 questions in total. Part 1 assessed demographic data, inquiring about gender, age, education, position at work, and religion. Part 2 measured the two dependent variables: commitment and employee engagement. The assessed the independent variable of religious discrimination. All items were measured on a 7-point scale ranging from "strongly agree" to "strongly disagree" with a neutral option.

Organizational Commitment: The researcher used the component model of commitment developed by Meyer and Allen (1997) to measure commitment. Sample items included "I do not feel emotionally attached to this organization," "I think that people these days move from company to company too often," and "right now, staying with my organization is a matter of necessity as much as desire." This multidimensional scale measures three types of commitment: affective, continuance, and normative. This scale has been used widely and tested intensively in different cultures (see Culpepper, 2000; Jaros, 1997). It includes 24 items, 8 items for each commitment type. Cronbach's alpha for Organizational Commitment was 0.706 in our sample.

Employee Engagement: The Utrecht Work Engagement Scale (UWES; Schaufeli et al., 2002) was used to assess employee engagement. Sample items include "at my job, I feel strong and vigorous," "I'm proud of the work I do," and "time flies when I am working." This multidimensional scale was empirically evaluated in many studies (see Dagher \& Junaid, 2010; Gonzales-Roma, Schaufeli, Bakker, \& Salanova, 2006). The UWES scale has 17 items, six measuring employee vigor (VIG), five measuring dedication (DED), and six measuring absorption (ABS). High scores on the Utrecht scale indicate high levels of employee engagement while low scores indicate lower levels of engagement. Cronbach's alpha for Employee Engagement was 0.958 in our study.

Religious Discrimination: In this study, this variable was used to elicit employees' perception about religious discrimination in their organizations. The researcher revised the Religious Diversity questionnaire by Messarra and El-Kassar (2010).The 17 revised statements were measured on a 7-point Likert scale. Sample items include "I believe I am not being paid a fair amount for the work I do because of my religion," "management respects the dress code of its employees with respect to their religious affiliation," and "my religion is a barrier to my career advancement." 
Next, to evaluate whether each item on the instrument measures the concept it is intended to measure (Punch, 2005), the researcher performed content validity analysis of the questionnaire using a quantitative approach (Lawshe, 1975). To validate the content of the survey, the questionnaire comprising 17 questions assessing religious discrimination was generated. These questions were then measured on a 3-point scale, "1= not necessary"; "2 = useful but not essential"; "3=essential".

Since the content validity was determined by expert judges who evaluated the appropriateness of the contents of a measure ( $\mathrm{Yu}, 2012), 20$ professionals were identified based on their daily work and involvement with workers with diverse religious backgrounds. The identified professionals were then contacted and emailed the questionnaire along with a cover letter that explained the purpose of the study and provided the instructions on the completion of the questionnaire. The responses were then sorted, and for each item a content validity ratio collated by counting the number of essential responses for each item within the questionnaire. For each item, a content validity ratio (CVR) was estimated and evaluated at a statistical level of significance of 0.05 (Lawshe, 1975). All 17 questions were valid.

The findings showed that all 17 questions in the survey should be included in the final questionnaire. The CVR value for all 17 constructs fell between a minimum of 0.75 and a maximum of 1 . This means that the questions in the survey had a high level of content validity. Thus, they were representative of the case at hand. Cronbach's alpha for the 17 questions was 0.89 .

The researcher then used exploratory factor analysis to identify the factors that may shape perceived religious discrimination in work settings, since there is no solid theory to explain it (Bartholomew et al., 2008) (see the result of the component factor analysis with varimax rotation in Appendix A).

Interpreting factor loadings. By the rule of thumb, loadings should be 0.7 or higher to confirm that independent variables identified a priori are represented by a particular factor, based on the rationale that the 0.7 level corresponds to about half of the variance in the indicator being explained by the factor. However, the 0.7 standard is too high, and the real-life data may not meet this criterion, which is why some researchers opt to use a lower level, such as 0.4 for the central factor and 0.25 for other factors, particularly for exploratory purposes. Loadings above 0.6 are "high" and those below 0.4 are "low" (see Hair, et al., 1998; Raubenheimer, 2004), which is why the researcher opted to choose 0.6 as a cutoff point. In any event, factor loadings must be interpreted in the light of the theory and not by an arbitrary cutoff level (Hair et al., 1998; Raubenheimer, 2004). One statement, "I believe managers observe equal 
opportunities when selecting or recruiting regardless of employee's religion," had a loading of less than 0.6 , thus it was removed.

Based on these results, the variables formed four factors (all related to religious discrimination), according to the absolute value criteria being greater than 0.6. F1 comprised 8 items related to religious affiliation; F2 comprised 3 items related to general perception; F3 comprised 2 items related to management practices; F4 comprised 3 items related to organization practices.

\section{FINDINGS}

The demographic results indicated that $72.8 \%$ of respondents were between 19 and 29 years of age, with 59.5\% females and 39.2\% males. Furthermore, 12.4\% had some college education or less, $45.99 \%$ had a BS/BA, and $39.41 \%$ had a master's degree or above. Additionally, $18.45 \%$ of the respondents worked in middle management while $65.32 \%$ held non-managerial positions. Many participants did not indicate their religion. This could be the result of the 15 years of sectarian civil war in Lebanon (1975-1990), which most respondents considered a sensitive issue.

\section{Regression Analysis}

In order to test the effect of perceived religious discrimination on organizational commitment and engagement, the researcher performed regression analysis.

The following regression equations tested the proposed hypotheses, with commitment variables as the dependent variables and the religious discrimination components as the independent variables.

H1a: Religious discrimination and affective commitment are negatively related.

The linear regression equation generated for religious discrimination and affective commitment is:

Affective Commitment $=4.117-0.064 \mathrm{~F} 1$ (religious affiliation) $-0.014 \mathrm{~F} 2$ (general perception) $+0.036 \mathrm{~F} 3$ (management practices) $+0.05 \mathrm{~F} 4$ (organization practices)

At 5\% level of significance, religious affiliation had a significant negative effect on affective commitment ( $p$-value $=0.00$ ) while organization practices had a significantly positive effect ( $p$-value $=0.006$ ). These factors accounted for $5.1 \%$ of total variance in affective commitment. On the other hand, both general perception and management practices had no significant effect.

H1b: Religious discrimination and normative commitment are negatively related.

The linear regression equation generated for religious discrimination and 
normative commitment:

Normative Commitment $=4.004+0.074 \mathrm{~F} 1$ (religious affiliation) $-0.071 \mathrm{~F} 2$ (religious affiliation) -0.024F3 (management practices) $+0.145 * \mathrm{~F} 4$ (organization practices)

At 5\% level of significance, organization practices had a highly significant positive effect on normative commitment ( $p$-value $=0.000)$ followed by religious affiliation ( $p$-value $=0.011)$. General perception had a negative effect $(p$-value $=0.0012$ ). These factors accounted for $7.4 \%$ of total variance in normative commitment. Management practices had no significant effect.

H1c: Religious discrimination and continuance commitment are negatively related.

The linear regression equation generated for religious discrimination and continuance commitment:

Continuance Commitment $=4.245+0.056 \mathrm{~F} 1$ (religious affiliation) $-0.023 \mathrm{~F} 2$ (religious affiliation)-0.191 F3 (management practices) +0.004 F4 (organization practices)

At 5\% level of significance, none of the different religious discrimination components had a significant effect on the dependent variable of continuance commitment.

The following regression equations were used to test the proposed hypotheses, with employee engagement variables as the dependent variables and the religious discrimination components as the independent variables.

H2a: Religious discrimination and vigor are negatively related.

The linear regression equation generated for religious discrimination and employee vigor:

Vigor $=4.467+0.402 \mathrm{~F} 1$ (religious affiliation) $+0.273 \mathrm{~F} 2$ (general perception) $-0.045 \mathrm{~F} 3$ (management practices) $+0.027 \mathrm{~F} 4$ (organization practices)

At $5 \%$ level of significance, religious affiliation $(p-v a l u e=0.000)$ and general perception ( $p$-value $=0.000$ ) had a significant positive effect on employee vigor. These two factors accounted for $24.6 \%$ of the variance in employee vigor. All other groups, i.e., organization practices and management practices, had no significant effect.

$\mathrm{H} 2 \mathrm{~b}$ : Religious discrimination and absorption are negatively related. 
The linear regression equation generated for religious discrimination and employee absorption:

Absorption $=3.83+0.422 \mathrm{~F} 1$ (religious affiliation) $+0.062 \mathrm{~F} 2$ (general perception) +0.073 F3 (management practices) -0.081 F4 (organization practices)

At 5\% level of significance, religious affiliation had a significant positive effect on employee absorption ( $\mathrm{p}$-value $=0.000$ ). This factor accounted for $11.5 \%$ of the variance in employee absorption. All other groups, i.e., organization practices, general perception, and management practices, had no significant effect.

H2c: Religious discrimination and dedication are negatively related.

The linear regression equation generated for religious discrimination and employee dedication:

Dedication $=4.75+0.478 \mathrm{~F} 1$ (religious affiliation) $+0.178 \mathrm{~F} 2$ (general perception) $+0.192 \mathrm{~F} 3$ (management practices) -0.036 F4 (organization practices)

At $5 \%$ level of significance, religious affiliation ( $p$-value $=0.000)$, general perception ( $p$-value $=0.001$ ), and management practices, $(p$-value $=0.001)$ had a significant positive effect on employee dedication. These factors accounted for $16.8 \%$ of the variance in employee dedication while organization practices had no significant effect.

\section{DISCUSSION AND CONCLUSION}

The research objective was to fill the gap in the literature and increase the level of organizational awareness about the importance of the effect of perceived religious discrimination on employee engagement and commitment. The results from this study add to the literature on religious discrimination and highlight the effect of religious discrimination on work-related behaviors, mainly commitment and engagement. Previous literature has linked these behaviors to organizations' overall outcomes (see Chen, Silverthorne, \& Hung, 2006; Macey \& Schnider, 2008).

Regarding commitment, the results partially supported our hypotheses (H1a, H1b, and $\mathrm{H} 1 \mathrm{c}$ ), which stated that religious discrimination and affective, normative, and continuance commitments are significantly negatively related. The results indicated that religious affiliation and affective commitment were negatively related. This is in line with the social categorization theory and the notion that employees perceive inequality among groups. Previous research by Ely and Thomas (2001) revealed that people who were racially and/or ethnically different from their work units were less psychologically committed to their organization. Thus, since perceived religious 
discrimination has been found to negatively influence commitment, employees who perceive religious discrimination may show decreased work performance and overall productivity. Accordingly, employees might become less emotionally attached to their organization and thus cling to their religious groups for support.

On the other hand, organizational practices showed a positive relationship with affective and normative commitments (inconsistent with the proposed hypothesis). This indicates that when organizations consider matters like employee religious food catering service needs, such as "Halal" or "Kosher" and do not prohibit certain religious practices (such as time for prayer or religious decorations), the employees' emotional attachment to their organization will most likely increase and their moral obligation to remain with that organization will also increase. Also, general perception indicated a negative relationship of organizational practices with normative commitment, that is, when employees perceive that they are being treated unfairly and discriminated against because of their religion, their emotional states, and thus their sense of obligation to remain in the organization, will be affected negatively.

Contrary to our expectations, continuance commitment did not have a significant relationship with any of the religious discrimination components. The reason could be that the longer employees remain in the organization, the more they become attached to it (Meyer, Allen, \& Smith 1993), which may alter their perception of religious discrimination. Further research could examine the relation between religious discrimination and continuance commitment using the number of years in the organization as a mediating variable.

Regarding employee engagement, the results are inconsistent with the hypotheses ( $\mathrm{H} 2 \mathrm{a}, \mathrm{H} 2 \mathrm{~b}$, and $\mathrm{H} 2 \mathrm{c}$ ), which stated that religious discrimination and vigor, dedication, and absorption (components of employee engagement) are significantly negatively related. Religious affiliation and general perception were both positively related to vigor. Religious affiliation, general perception, and management practices were all positively related to dedication, and religious affiliation had a positive relation with absorption. It can be argued that since Lebanon is considered a high power distance culture (Hofstede, Hofstede, \& Minkov, 2010), people culturally accept a hierarchical order that needs no justification. As such, inequality may be tolerated in organizations. Moreover, Lebanon is a collectivist society/culture in which individuals base their identities on the religious group to which they belong, relationships are deemed more important than individuals or tasks, and promotion decisions are based on group membership within organizations (Hofstede, Hofstede, \& Minkov, 2010).

It is not surprising that 'religious affiliation' (religion being the basis for categorization in Lebanon) indicated a relation with many of the different dimensions. 
According to McDaniel (2004), religion in Lebanon often determines social and political identification. Even groups like professional associations, sports clubs, private universities and schools, and the media, to name a few, have confessional characteristics (Kiwan, 2005).

In conclusion, although religious discrimination has become an increasingly important topic post-9/11, it has gained little attention in management literature. This study was unique since it examined employees' perceived religious discrimination and its effect on their commitment and engagement. The findings suggest that when workers perceive religious discrimination in their organization, their commitment and engagement are affected. This is in agreement with Skuturna (2006) who indicated that a key element of employee satisfaction and engagement is satisfaction with diversity, including religious diversity, which increases productivity. However, it must be considered that these results could be culturally specific. It is recommended that companies work on minimizing the perception of religious discrimination in the workplace to strengthen their employees' organizational commitment and engagement.

\section{MANAGERIAL IMPLICATIONS}

The theoretical contribution of this research is that it contributes new knowledge to the literature on religious discrimination and links religious discrimination in the workplace to behavioral outcomes (mainly commitment and engagement).

On the practical side, according to Morrison (1996) and Loden and Rosenor (1991), organizations that manage diversity well enjoy higher productivity and rates of retention, and they have the ability to recruit high- potential candidates. Thus, in a world where workforce diversity is a major challenge for many organizations and where religious diversity is becoming more of a concern, it is recommended that top management develops religious discrimination policies and clearly communicates these policies to all organizational members as a part of their corporate values. Second, managers in general and specifically human resource managers take proactive stance to avoid costly behavioral outcomes. They need to devise strategies, and develop management interventions to mitigate negative organizational and personal consequences of religious discrimination in the workplace. Mentoring, coaching, and religious diversity training can enhance employee awareness of these negative consequences, can help change general perception and behavior, and can encourage a positive diversity climate. Regular and specialized training opportunities have been shown to be very effective in modifying employee perceptions of, for example, discrimination (Hanover \& Cellar, 1998). HR practitioners should adopt proactive 
measures that foster a just and inclusive culture of equality among workers as a key element of employee satisfaction.

\section{LIMITATIONS AND FUTURE RESEARCH}

This research has a number of limitations. First, the data was collected from a small sample size from the private sector in Lebanon. Therefore, the results cannot be generalized on a larger scale. Further research is needed to extend this study to other cultures and to identify differences between the private and public sector, if any. Second, data collection was carried out using questionnaires, which may not capture the true, unbiased responses of the respondents. Future research may consider complementary interviews to yield results that would be more accurate. Third, further studies could assess the effect of employees' perceived religious discrimination on other behavioral outcomes, such as job satisfaction, turnover, and absenteeism. Finally, demographic results indicated that most respondents were females and relatively young college graduates. Other studies could target different groups to validate our results.

\section{REFERENCES}

Abdul Rashid, Z., Sambasivan, M. and Johari, J. (2003). The influence of corporate culture and organizational commitment on performance. Journal of Management Development, 22(8), 708-728. http://dx.doi.org/10.1108/02621710310487873

Allen, N. J. and Meyer, J. P. (1990). The Measurement and Antecedents of Affective, Continuance, and Normative Commitment to the Organization. Journal of Occupational Psychology, 63, 1-18. http://dx.doi.org/10.1111/j.20448325.1990.tb00506.x

Aoun, G. (2007). Report of an international forum on managing diversity. Equal $\begin{array}{lllll}\text { Opportunities } & \text { International, 26(1), } & 67 & - & 70 .\end{array}$ http://dx.doi.org/10.1108/02610150710726534

Avey, J. B., Wernsing, T. S., and Luthans, F. (2008). Can positive employees help positive organizational change? Impact of psychological capital and emotions on relevant attitudes and behaviors. The Journal of Applied Behavioral Science, 44(1), 48-70. http://dx.doi.org/10.1177/0021886307311470

Baek-Kyoo, B. J., and Taejo, L. (2009). The effects oforganizational learning culture, perceived job complexity, and proactive personality on organizational commitment and intrinsic motivation. Journal of Leadership and Organizational Studies, 16(1), 48-60. 
Bartholomew, D., Steele, F., Galbraith, J and Moustaki, I. (2008). Analysis of multivariate social science data. FL: Chapman \& Hall.

Bono, J. E., and Judge, T. A. (2003). Core self-evaluations: A review of the trait and its role in job satisfaction and job performance. European Journal of Personality, 17, S5 - S18. http://dx.doi.org/10.1002/per.481

Borstorff, P., and Arlington, K. (2011). Protecting religion in the workplace? What employees think. Journal of Legal, Ethical and Regulatory Issues, 14(1), 59-70.

Brown, S. P. (1996). A meta-analysis and review of organizational research on job involvement. Psychological Bulletin, 120, 235-255. http://dx.doi.org/10.1037/0033-2909.120.2.235

Cantone, J. A. (2011). Religion at work: Evaluating hostile work environment religious discrimination claims. (Doctoral dissertation), Available from http://digitalcommons.unl.edu/psychdiss

Cavanagh, G. (1999). Spirituality for managers: context and critique. Journal of Organizational Change Management, 12(3), 186-199. http://dx.doi.org/10.1108/09534819910273793

Chan, A. (2011, February). The challenges of human resource management. Retrieved from http://aassco.com/public/user_data/challenges-of-human-resourcemanagement.pdf

Channar, Z. A., Abbassi, Z., and Ujan, I. A. (2011). Gender discrimination in workforce and its impact on the employees. Pak. J. Commer. Soc. Sci, 5(1), 177191.

Chen, J., Silverthorne, C., and Hung, J. (2006). Organization communication, job stress, organizational commitment, and job performance of accounting professionals in Taiwan and America. Leadership and Organization Development Journal, 27(4), 242-249. http://dx.doi.org/10.1108/01437730610666000

Culpepper, R. A. (2000). A test of revised scales for the Meyer and Allen (1991) three-component commitment construct. Educational and Psychological Measurement, 60 (4), 604-616. http://dx.doi.org/10.1177/00131640021970754

Dagher, G., and Junaid, N. (2010). Emotional intelligence, employee engagement, and job stress: An empirical investigation. Business Studies Journal, 2(1), 107-116.

Dajani, N. (1992). Disoriented media in a fragmented society: The lebanese experience. Beirut: American University of Beirut.

Day, N. E. (2005). Religion in the workplace: Correlates and consequences of individual behavior. Journal of Management, Spirituality and Religion, 2(1), 104-135. http://dx.doi.org/10.1080/14766080509518568 
Dipboye, R.L., and Colella, A. (2005). The dilemmas of workplace discrimination. In Dipboye, R.L, and Colella, A. (Eds.), Discrimination at work the psychological and organizational bases, 425-462. Mahwah, NJ: Lawrence Erlbaum.

Ensher, E.A., Grant-Vallone, E.J. and Donaldson, S.I. (2001). Effects of perceived discrimination on job satisfaction, organizational commitment, organizational citizenship behavior, and grievances. Human Resource Development Quarterly, 12(1), 53-72. http://dx.doi.org/10.1002/1532-1096(200101/02)12:1\%3C53::AIDHRDQ5\%3E3.3.CO;2-7

Equal Employment Opportunity Commission (2011). Religion-based Charges. FY 1997 - $\quad$ FY 2010. Retrieved from: http://www.eeoc.gov/eeoc/statistics/enforcement/religion.cfm.

Ely, R. J., and Thomas, D. A. (2001). Cultural diversity at work: The effects of diversity perspectives on work group processes and outcomes. Administrative Science Quarterly, 46(2), 229-273. http://dx.doi.org/10.2307/2667087

Gelade, G. A., Dobson, P., and Gilbert, P. (2006). National differences in organizational commitment: Effect of economy, product of personality, or consequence of culture? Journal of Cross-Cultural Psychology, 37, 542-556. http://dx.doi.org/10.1177/0022022106290477

Ghazi, A. (1997, September 30). Lebanon's culture. Retrieved from: http://www.ghazi.de/society.htm

Gonzalez-Roma, V., Schaufeli, W., Bakker, A., and Lioret, S. (2006). Burnout and work engagement: Independent factors or opposite poles? Journal of Vocational Behavior, 68(1), 165-174. http://dx.doi.org/10.1016/j.jvb.2005.01.003

Hair, J. F., Anderson, R. E., Tatham, R. L., and Black, W. C. (1998). Multivariate data analysis with readings. (5 ed.). NJ: Englewood Cliffs, NJ: Prentice-Hall.

Hanover, J.M.B., and Cellar, D. F. (1998). Environmental factors and the of workforce diversity training. Human Resource Development Quarterly, 9(2), 105-127. http://dx.doi.org/10.1002/hrdq.3920090203

Harter, J.K., Schmidt, F.L. and Keyes, C.L.M. (2003). Well-being in the workplace and its relationship to business outcomes: A review of the Gallup studies. In C.L.M. Keyes and J. Haidt (Eds.), Flourishing, positive psychology and the life well-lived. Washington DC: American Psychological Society, 205-224.

Hofstede, G., Hofstede, G. J. and Minkov, M. (2010). Cultures and Organizations: Software of the Mind (3 Ed.). USA : McGraw-Hill.

Hudson, M. (1999). Lebanon after Ta'if: another reform opportunity lost. Arab Studies Quarterly, 21(1), 27-35 
Jaros, S. J. (1997). An Assessment of Meyer and Allen's (1991) Three- Component Model of Organizational and Turnover Intentions. Journal of Vocational Behavior, 51 (3), 319-337.

Kahn, W.A. (1990). Psychological conditions of personal engagement and disengagement at work. Academy of Management Journal, 33, 692-724. http://dx.doi.org/10.2307/256287

Kiwan, F. (2005). Consolidation ou recomposition de la société civile d'après guerre? (composition or re-composition of the after war civil society). Confluences Méditerranée, 47.

Lawshe, C. H. (1975). A quantitative approach to content validity. Personnel Psychology, 28(4), 563-575. http://dx.doi.org/10.1111/j.17446570.1975.tb01393.x

Loden, M., and Jackson, J.S. (1991). Workforce America! Managing employee diversity as a vital resource. Burr Ridge, IL: Irwin.

Macey, W. H., and Schneider, B. (2008). The meaning of employee engagement. Industrial and Organizational Psychology, 1(1), 3-30. http://dx.doi.org/10.1111/j.1754-9434.2007.0002.x

Major, B., and O'Brien, L. T. (2005). The social psychology of stigma. Annual Review of Psychology, 56, 393-421. http://dx.doi.org/10.1146/annurev.psych.56.091103.070137

Maktabi, R. (1999). The Lebanese census of 1932 revisited. Who are the Lebanese? British Journal of Middle Eastern Studies, 26(2), 219-241. http://dx.doi.org/10.1080/13530199908705684

Markos, S., and Waltair, V. (2010). Employee engagement: The key to improving performance. International Journal of Business and Management. 5(12), 89-96

Markwick, K. and Smith G.R. (2009). Employee Engagement: A Review of Current Thinking. Retrieved

from: http://www.nhsemployers.org/SiteCollectionDocuments/Staff $\% 20$ engagement $\% 2$ 0current $\% 20$ thinking.pdf

Maslach, C., Schaufeli, W.B. and Leiter, M.P. (2001). Job burnout. Annual Review of Psychology, 52(1), 397-422. http:// 10.1146/annurev.psych.52.1.397

Mathieu, J. E., and Zajac, D. M. (1990). A review and meta-analysis of the antecedents, correlates, and consequences of organizational commitment. Psychological Bulletin, 108, 171-194. http://dx.doi.org/10.1037//00332909.108.2.171

McDaniel, J. (2004). Lebanon: Modern Middle East Nation and their Strategic Place in the World. Philadelphia: Mason Crest Publications. 
Messarra, L. C. and El-Kassar, A. (2010). Effects of religious diversity on the employees' perception and reaction. The Business Review, 15(1), 159-163.

Meyer, J. P. and Allen, N.J. (1997). Commitment in the workplace: Theory, research, and application. Thousand Oaks, Sage Publications.

Meyer, J. P., Allen, N. J., and Smith, C. A. (1993). Commitment to organizations and occupations: Extension and test of a three-component conceptualization. Journal of Applied Psychology, 78(4), 538-551. http://dx.doi.org/10.1037/00219010.78.4.538

Mitroff, I. and Denton, E. (1999). A Spiritual Audit of Corporate America: A Hard Look at Spirituality, Religion, and Values in the Workplace. San Francisco: Jossey-Bass.

Morgan, J. (2004). How should business respond to a more religious workplace? SAM Advanced Management Journal, 69(4), 11-19.

Morrison, A.M. (1996). The new leaders: Leadership diversity in America. San Francisco: Jossey-Bass.

Mowday, R. T., Porter, L. M., and Steers, R. M. (1982).Employee-organization linkages: The psychology of commitment, absenteeism, and turnover. (p. 27). New York, NY: Academic Press.

Oliveira, Arnaldo (2004). The place of spirituality in organizational theory. Electronic Journal of Business Ethics and Organization Studies (EJBO), 9(2), 17-22XX.

Perrin, T. (2003). Working Today: Understanding What Drives Employee Engagement The 2003 Towers Perrin Talent Report U.S Report. Retrieved from: http://www.towersperrin.com/tp/getwebcachedoc?webc=hrs/usa/2003/200309/tal ent_2003.pdf

Punch, K. F. (2005). Introduction to social research: Quantitative and qualitative approaches. London: Sage.

Rabl, T., and del Carmen Triana, M. (2013). How German employees of different ages conserve resources: Perceived age discrimination and affective organizational commitment. The International Journal of Human Resource Management. http://dx.doi.org/10.1080/09585192.2013.777936

Raubenheimer, J. E. (2004). An item selection procedure to maximize scale reliability and validity. South African Journal of Industrial Psychology, 30(4), 59-64.

Religious Discrimination. (June 4, 2013). In: Wikipedia. Retrieved from: http://en.wikipedia.org/wiki/Religious_discrimination

Riketta, M. (2002).Attitudinal organizational commitment and job performance: A meta-analysis. Journal of Organizational Behavior, 23(3), 257-266. http://dx.doi.org/10.1002/job.141 
Robbins, S. P., and Judge, T. A. (2013). Organizational behavior. (15 ed.). Pearson Education Inc.

Shellenbarger, S. (1993, Sept. 3). Workforce study finds loyalty is weak, divisions of race and gender are deep. Wall Street Journal, B1.

Sanchez, J. I., and Brock, P. (1996). Outcomes of perceived discrimination among Hispanic employees: Is diversity management a luxury or a necessity? Academy of Management Journal, 39(3), 704-719. http://dx.doi.org/10.2307/256660

Schaufeli, W., Bakker, A. and Salanova, M. (2006). The Measurement of Work Engagement with a Short Questionnaire. Educational and Psychological Measurement, 66: 701-116. http://dx.doi.org/10.1177/0013164405282471

Schaufeli, W. B., and Van Rhenen, W. (2006). On the role of positive and negative emotions in the wellbeing of managers: A study of the job-related Affective Well-being Scale (JAWS). Behavior and Organization, 19, 323-244.

Schaufeli, W.B., Salanova, M., Gonza'lez-Roma', V. and Bakker, A.B. (2002). The measurement of engagement and burnout: A confirmative analytic approach. Journal of Happiness Studies, 3, 71-92.

Seijts, G. and Crim, D. (2006). What engages employees the most or, the Ten C's of employee engagement. Ivey Business Journal Online, 1-5.

Skuturna, J. (2006). Employee Engagement and Diversity Satisfaction Linkage Identifier, Retrieved from: http://www.hrsolutionsinc.com

Thompson, V. L. S. (1999). Variables affecting identity salience among African Americans. Journal of Social Psychology, 139, 748-761. http://dx.doi.org/10.1080/00224549909598254

Van Knippenberg, D., De Dreu, C. K.W. and Homan, A. C. (2004).Work group diversity and group performance: An integrative model and research agenda. Journal of Applied Psychology, 89, 1008-1022. http://dx.doi.org/10.1037/00219010.89.6.1008

Weiss, D.C. (2008, Oct. 16). Meatpacker Prayer Dispute Among Rising Complaints of Religious Bias. American Bar Association Journal. Retrieved from: http://www.abajournal.com/mobile/article/meatpacker_prayer_dispute_among_ri sing_complaints_of_religious_bias/

Wilson, T. (1997). Diversity at work: The business case for equity. New York: John Wiley.

Wolkinson, B. and Nichol, V. (2008). Religious discrimination: Arbitrating the grievances. Dispute Resolution Journal, 54-63.

$\mathrm{Yu}$, C. H. (2012). Reliability and Validity. Retrieved from: www.creativewisdom.com/teaching/assessment/reliability.html

Zikmund, W. G. (2002).Business research methods ( $7^{\text {th }}$ ed.). New York: South Western Publications. 


\section{APPENDIX A}

\begin{tabular}{|c|c|c|c|c|}
\hline \multicolumn{5}{|c|}{ Rotated Component Matrix ${ }^{a}$} \\
\hline & \multicolumn{4}{|c|}{ Component } \\
\hline & 1 & 2 & 3 & 4 \\
\hline Q13R & .817 & & & \\
\hline Q16R & .784 & & & \\
\hline Q17R & 687 & & & \\
\hline Q15R & .672 & & & \\
\hline Q5 & .657 & & & \\
\hline Q6 & .640 & & & \\
\hline Q7 & .634 & & & \\
\hline Q14R & .622 & & & \\
\hline Q2R & & .724 & & \\
\hline Q4R & & .698 & & \\
\hline Q1R & & .681 & & \\
\hline Q9 & & & & \\
\hline Q8 & & & & \\
\hline $\mathrm{Q} 12$ & & & & .775 \\
\hline Q11 & & & & .617 \\
\hline Q10R & & & & .601 \\
\hline
\end{tabular}

Extraction Method: Principal Component Analysis.

Rotation Method: Varimax with Kaiser Normalization.

a. Rotation converged in 18 iterations. 
